OPEN ACCESS

Edited by:

Daniela D. Pollak,

Medical University of Vienna, Austria

Reviewed by:

Axel Steiger

Max Planck Institute of Psychiatry,

Germany

Toru Takumi,

Riken Brain Science Institute, Japan

Rae Silver,

Columbia University, USA

${ }^{*}$ Correspondence:

Urs Albrecht

urs.albrecht@unifr.ch

Specialty section:

This article was submitted to

Sleep and Chronobiology,

a section of the journal

Frontiers in Neurology

Received: 06 December 2016 Accepted: 23 January 2017

Published: 07 February 2017

Citation:

Albrecht U (2017) Molecular

Mechanisms in Mood Regulation

Involving the Circadian Clock.

Front. Neurol. 8:30.

doi: 10.3389/fneur.2017.00030

\section{Molecular Mechanisms in Mood Regulation Involving the Circadian Clock}

\author{
Urs Albrecht* \\ Department of Biology, Unit of Biochemistry, University of Fribourg, Fribourg, Switzerland
}

The circadian system coordinates activities and functions in cells and tissues in order to optimize body functions in anticipation to daily changes in the environment. Disruption of the circadian system, due to irregular lifestyle such as rotating shift work, frequent travel across time-zones, or chronic stress, is correlated with several diseases such as obesity, cancer, and neurological disorders. Molecular mechanisms linking the circadian clock with neurological functions have been uncovered suggesting that disruption of the clock may be critically involved in the development of mood disorders. In this mini-review, I will summarize molecular mechanisms in which clock components play a central role for mood regulation. Such mechanisms have been identified in the monoaminergic system, the HPA axis, and neurogenesis.

Keywords: clock genes, depression, monoamines, glucocorticoids, neurogenesis

A plethora of human genetic studies have identified polymorphisms in clock genes that associate with psychiatric disorders [reviewed in Ref. (1)]. This suggested that abnormalities in clock genes may be one of the causes for the development of mood disorders. At the cellular level, clock genes (Bmal1, Clock, Per, Cry, Rev-erb, and Ror) make up an autoregulatory transcriptional/translational feedback loop with a period of about $24 \mathrm{~h}$ (Figure 1, top gray circle) [reviewed in Ref. (2)]. These clock genes and their proteins not only self-promote their own temporally fluctuating transcription but they also regulate transcription of target genes (Figure 1) and/or modulate key molecular pathways via protein-protein interactions, such as the monoaminergic system, the HPA axis, or neurogenic pathways.

\section{TRANSCRIPTIONAL REGULATION OF MONOAMINE SIGNALING BY CLOCK COMPONENTS}

Neuroimaging studies in humans indicated that the monoaminergic system (dopamine, serotonin, and noradrenaline) was altered in subjects with mood disorders (3). This was further supported by optogenetic studies, in which control of neuronal activity of dopamine neurons in mice modulated mood, anxiety, and reward, confirming the importance of the monoaminergic system in moodrelated behaviors $(4,5)$.

Interestingly, several studies described daily changes in dopamine, serotonin, and noradrenaline levels [reviewed in Ref. (6)]. Because these molecules modulate arousal, motivation, and reward, one would expect them to be targeted at the activity period of the day in order to avoid conflicts with sleep signals. Hence, monoaminergic signaling is likely to be regulated by the circadian clock, either directly or indirectly. In the last years, several investigations aimed at uncovering the role of circadian clock components in the direct transcriptional regulation of 


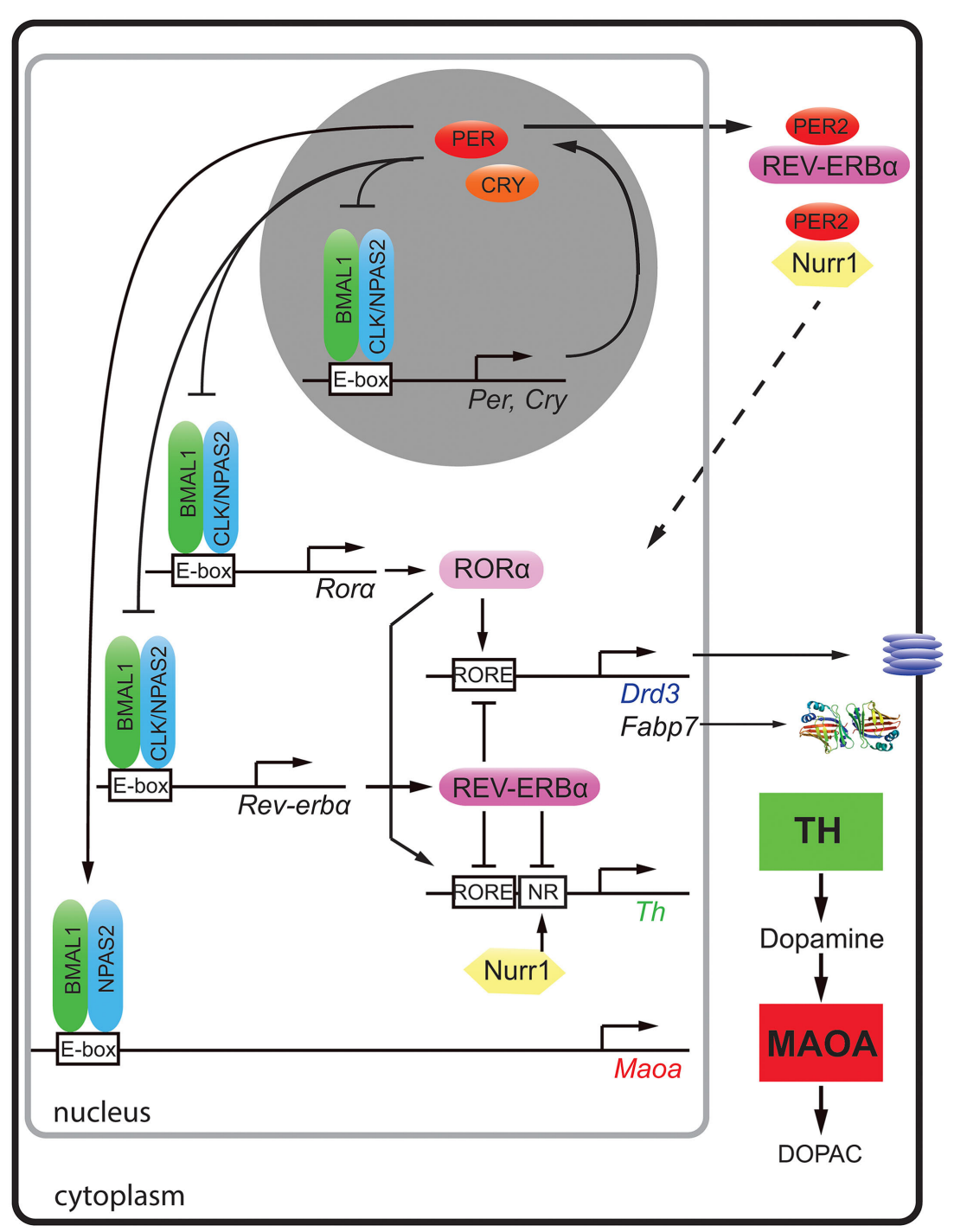

FIGURE 1 | Molecular regulation of clock and clock-controlled genes of the monoaminergic system and neurogenesis. The clock proteins BMAL1 (green), CLOCK (blue), and NPAS2 (blue) bind to E-box elements present in the promoters of clock genes (Per, Cry, Ror $\alpha$, and Rev-erb $\alpha$ ) and the clock-controlled gene for monoamine oxidase A (Maoa). PER (red) and cryptochrome (CRY, orange) proteins inhibit the action of BMAL1/CLOCK and BMAL1/NPAS2 heterodimers, respectively. The nuclear receptors [retinoic orphan receptor $\alpha(R O R \alpha$, rose)] and REV-ERB $\alpha$ (purple) both bind to RORE elements of dopamine receptor 3 (Drd3), fatty acid binding protein 7 (Fabp7), and tyrosine hydroxylase (Th) in a competitive manner and activate or inhibit their expression, respectively. The nuclear receptor Nurr1 (yellow) regulates Th via its NR promoter element. Via protein-protein interactions, PER2 can modulate the actions of REV-ERB $\alpha$ and Nurr1 (hatched arrow). This regulation results in temporally regulated expression of the dopamine synthesizing (TH, green square) and degrading enzymes (MAOA, red square) leading to fluctuating levels of dopamine in the striatum.

elements important for monoaminergic signaling, such as the enzymes monoamine oxidase (MAO) and tyrosine hydroxylase (TH) both key enzymes for the degradation and synthesis of dopamine, respectively.

Dopamine degradation is under clock control. This was first suggested by the observation that the clock components BMAL1 and NPAS2 transcriptionally activated a luciferase reporter driven by the murine monoamine oxidase A ( $\mathrm{Maoa}$ ) promoter in a circadian fashion. This indicated that these two clock components directly regulated Maoa transcription (Figure 1). This notion was further strengthened by the observation that
BMAL1 protein was recruited to the Maoa promoter in brain tissue (7). Interestingly, the regulation by BMAL1/NPAS2 was modulated by PER2 in a positive fashion, but not in the predicted negative manner (Figure 1). This lead to increased Maoa mRNA levels (7). This finding suggested potential tissue specific regulatory factors that turned PER2 into a positive regulator of BMAL1/NPAS2-driven transcriptional regulation in the striatum. As a consequence of lack of PER2, not only Maoa mRNA but also MAOA protein levels were decreased. Hence, dopamine degradation was reduced, and dopamine levels in the nucleus accumbens were increased. This was paralleled by 
a depression-resistant-like phenotype and changes in neuronal activity in response to MAO inhibitors in mice (7). These findings strongly suggested that the degradation of monoamines was clock modulated. It is very likely that the described clockmediated regulation of monoamines is relevant for humans, because single-nucleotide polymorphisms in Per2, Bmal1, and Npas 2 associated in an additive fashion with seasonal affective disorder or winter depression (8).

A recent study showed that not only dopamine degradation but also dopamine synthesis is under clock influence. The mouse, rat, and human Th promoters were repressed by REV-ERB $\alpha$, and they were activated by retinoic orphan receptor $\alpha(\operatorname{ROR} \alpha)$ and nuclear receptor-related protein 1 (NURR1) (9). Chromatin immunoprecipitation experiments revealed that $\mathrm{REV}-\mathrm{ERB} \alpha$ and NURR1 were binding to the Th promoter in an antagonistic manner (9). In accordance with this mechanism (Figure 1), Reverb $\alpha$ knock-out mice displayed elevated Th mRNA and protein levels leading to increased dopamine amounts and firing rate in the striatum $(9,10)$. As a consequence, these animals showed less depression-like and anxiety-like behavior compared to wildtype animals (9). The temporal regulation of TH may be further modulated through protein-protein interactions. For example, PER2 has the potential to interact with both REV-ERB $\alpha$ and NURR1 proteins (11), which would allow temporal synchronization of the action of these two nuclear receptors (Figure 1, top right, hatched arrow). This is, however, a speculation and needs verification.

Interestingly, $\mathrm{REV}-\mathrm{ERB} \alpha$ and $\mathrm{ROR} \alpha$ were described to regulate the expression of the dopamine D3 receptor gene (Drd3) in an antagonistic manner (12) (Figure 1). This provided a molecular explanation why this receptor was expressed in a diurnal manner in the striatum (13). DRD3 inhibits adenylyl cyclase through inhibitory G-proteins [reviewed in Ref. (14)] and mutation of DRD3 in mice suggested an involvement of this receptor in mediating emotional behavior and depression in mice (15). A role of NPAS2 in the regulation of Drd 3 has also been suggested (16), although it is unclear how NPAS2 would regulate the $\operatorname{Drd} 3$ promoter. Taken together, it appears that $\mathrm{REV}-\mathrm{ERB} \alpha$ and $\mathrm{ROR} \alpha$ synchronize dopamine production and the expression of DRD3 in the striatum probably to optimally restrict dopamine signaling in the striatum to a particular time window. This implies that the targeting of DRD3 and/or REV-ERB $\alpha / R O R \alpha$ by pharmacological agents may benefit from timed application. This would reduce dosage and diminish side effects such as weight gain, which is observed often in patients treated for mood disorders.

\section{MOLECULAR REGULATION OF COMPONENTS OF THE HPA AXIS BY CLOCK PROTEINS}

Epidemiological studies suggested that stressful life events play a role in the etiology of depression (17), and hypercortisolemia was observed in a subset of patients with depression [reviewed in Ref. (18)]. Furthermore, antidepressant treatment appeared to stabilize the function of the HPA axis via the serotonergic system (19), suggesting an involvement of the HPA axis and glucocorticoids in mood regulation [reviewed in Ref. (20)].

Conditional mutagenesis in mice of the glucocorticoid receptor (GR) in the nervous system provided evidence for the importance of GR signaling in emotional behavior (21). Overexpression of GR lead to depressive-like behavior, and these mice showed enhanced sensitization to cocaine (22), consistent with observations that GR may be a potential target to reduce cocaine abuse (23). Interestingly, GR bound to NURR1 thereby increasing the transcriptional potential of NURR1 to induce TH (24) (Figure 1). Hence, the amount of nuclear GR appeared to be important for this function. Although glucocorticoids displayed circadian rhythmicity [reviewed in Ref. (25)], GR expression was constant over $24 \mathrm{~h}$ in the liver, which applies most likely to the brain as well. However, GR nuclear localization appeared to be gated by $\mathrm{REV}-\mathrm{ERB} \alpha$ in the liver with nuclear GR levels high at zeitgeber time 20 (activity period of mice) (26). If this would apply to the brain, REV-ERB $\alpha$ would gate binding of GR to NURR1 for induction of the Th promoter (Figure 2). As illustrated above, mood-related behavior and dopamine levels were changed in Rev-erb $\alpha^{-/-}$mice, and this may also involve GR, which regulates catechol-O-methyltransferase (26), an enzyme degrading the MAOA product 3,4-dihydroxyphenylacetic acid to homovanillic acid. Therefore, it is likely that the monoaminergic system and the glucocorticoid pathway are linked via GR.

The cryptochrome (CRY) proteins interact with GR in a ligand-dependent manner in mouse liver leading to rhythmic repression of GR activity (27). Additionally, the CRY proteins participate in glucocorticoid-dependent suppression of the HPA axis and the production of endogenous glucocorticoids (27). Mice

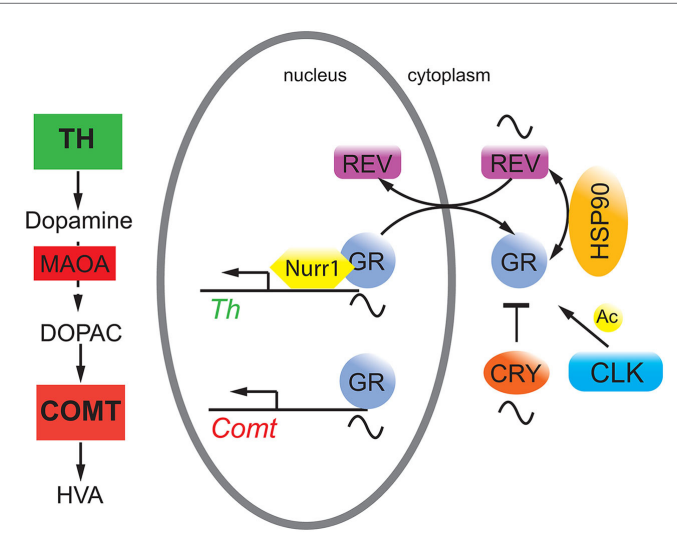

FIGURE 2 | Hypothetical model on the interaction of circadian clock proteins with the glucocorticoid receptor (GR). REV-ERB $\alpha$ (REV, purple) gates nuclear localization of the GR (gray) via an unknown mechanism probably involving heat shock protein 90 (HSP90, yellow). GR function is inhibited by cryptochrome (CRY, orange) proteins and is modulated by CLOCK (blue) via acetylation (Ac), although it is unclear whether this happens in the cytoplasm and/or the nucleus. GR regulates target genes such as catechol-O-methyltransferase (Comt) whose protein is an enzyme (COMT, red square) that degrades 3,4-dihydroxyphenylacetic acid (DOPAC) to homovanillic acid (HVA). GR may also interact with Nurr1 to modulate tyrosine hydroxylase (Th) expression thereby influencing dopamine production. 
lacking Cry1 showed depression-like behavior combined with reduced levels of dopamine in the striatum (28). This phenotype was most likely the result of the effects of CRY on both pathways illustrated in Figures 1 and 2. Furthermore, GR was acetylated by CLOCK, which lead to decreased sensitivity to glucocorticoids in the morning in humans and to an increased sensitivity at night when acetylation was reversed (29).

Recently, CHRONO, a protein that acts as a repressor in the circadian clock mechanism similar to CRY2 appeared to have the potential to interact with GR as well (30). Interestingly, Chrono mRNA was induced in the hypothalamus after stress stimulation whereas Cry 2 mRNA was not. This suggested that CHRONO may be a stress-inducible repressor of the circadian clock coupling the clock with the HPA axis (30). However, it is not known whether Chrono knock-out mice display alterations in mood-related behaviors.

\section{TRANSCRIPTIONAL REGULATION OF NEUROGENESIS BY CLOCK PROTEINS}

Adult neurogenesis is an important process to replace lost or dysfunctional neurons with new neurons produced from neuronal stem cells. Most of them are found in the subventricular zone lining the lateral ventricles and the subgranular zone of the hippocampal dentate gyrus. Environmental stimuli, such as stress, physical activity, sleep deprivation, enriched living conditions, and jet-lag, can influence adult hippocampal neurogenesis in mammals (31-35). These environmental stimuli directly affect the circadian clock as well [reviewed in Ref. (36)], suggesting that the clock plays a mediator role between environmental change and neurogenesis. Animal studies showed that chronic stress and depression-inducing behavior reduced hippocampal neurogenesis while antidepressants enhanced it (37), suggesting a connection between neurogenesis and depressive behavior (38). Hence, change of the clock by environmental stimuli may affect neurogenesis, which in turn affects mood-related behaviors. Interestingly, neurogenesis varied over the day (39-42), and mutations in clock genes affected adult hippocampal neurogenesis $(28,43-46)$. The effect of the clock on this process was at least in part due to the control of the timing of cell-cycle entry and exit of quiescent neural progenitor cells (QNPs) (47). For example, absence of Per 2 abolished the gating of cell-cycle entrance of QNPs $(43,47)$, whereas lack of Bmal1 resulted in constitutively high levels of proliferation and delayed cell-cycle exit $(46,47)$.

On the molecular level evidence of direct clock gene-mediated regulation of neurogenesis is scarce. The mechanism of

\section{REFERENCES}

1. Bellivier F, Geoffroy PA, Etain B, Scott J. Sleep- and circadian rhythm-associated pathways as therapeutic targets in bipolar disorder. Expert Opin Ther Targets (2015) 19:747-63. doi:10.1517/14728222.2015.1018822

2. Takahashi JS. Molecular components of the circadian clock in mammals. Diabetes Obes Metab (2015) 17(Suppl 1):6-11. doi:10.1111/dom.12514

3. Meyer JH. Applying neuroimaging ligands to study major depressive disorder. Semin Nucl Med (2008) 38:287-304. doi:10.1053/j.semnuclmed.2008. 02.007
Clock- and Bmal1-mediated neuronal differentiation appeared to be associated with the neurogenic transcription factor NeuroD1 (48), although a direct regulation of its promoter by clock genes was not shown. In contrast, the regulation of fatty acid binding protein 7 ( Fabp7), also termed brain lipidbinding protein, by the clock component REV-ERB $\alpha$ has been elucidated (44). FABP7 facilitates the solubility of long-chain fatty acids and is implicated in cell growth and differentiation (49). It affects neuronal differentiation (50) and is a marker for neuronal progenitor cells $(51,52)$. The promoter of the Fabp7 gene was directly suppressed by REV-ERB $\alpha$, and this suppression was relieved by ROR $\alpha$, a positive competitor of REV-ERB $\alpha$ (Figure 1) (44). Mice lacking Rev-erb $\alpha$ displayed increased levels of FABP7, which was associated with alterations in moodrelated behaviors, changes in hippocampus-dependent cognitive performance, and increased hippocampal neurogenesis (44).

Taken together, this overview illustrates multiple levels of molecular mood regulation with REV-ERB $\alpha$ (and PER2 as REV$\mathrm{ERB} \alpha$ modulator) being involved in all of the processes described; regulation of the monoaminergic system, the HPA axis, and neurogenesis.

In the future, a better understanding of the hypothetical molecular processes illustrated in Figure 2 will be of great importance, because it is unknown whether CRY and CLOCK affect GR function in the nucleus or the cytoplasm. This would distinguish whether the influence of these two clock components is directly on transcription or on modulation of GR protein stability and transport, which would influence GR-mediated transcription in an indirect manner. Furthermore, the posttranslational regulation of REV-ERB $\alpha$ is poorly understood with the exception of its residues S55/S59, which are phosphorylated by GSK3 $\beta$ and may mediate cellular sensitivity to lithium (53). Time-of-daydependent phosphorylation sites on REV-ERB $\alpha$ and GR (54) may contribute to the gated regulation of nuclear presence of these two receptors and hence on the regulation of metabolism and mood-related behaviors.

\section{AUTHOR CONTRIBUTIONS}

UA wrote the manuscript and prepared the figures.

\section{ACKNOWLEDGMENTS}

The author thanks Dr. Andrea Brenna and Dr. Jürgen Ripperger for comments on the manuscript. The support by the Velux Foundation and the Swiss National Science Foundation is gratefully acknowledged.

4. Chaudhury D, Walsh JJ, Friedman AK, Juarez B, Ku SM, Koo JW, et al. Rapid regulation of depression-related behaviours by control of midbrain dopamine neurons. Nature (2013) 493:532-6. doi:10.1038/nature11713

5. Tye KM, Mirzabekov JJ, Warden MR, Ferenczi EA, Tsai HC, Finkelstein J, et al. Dopamine neurons modulate neural encoding and expression of depression-related behaviour. Nature (2013) 493:537-41. doi:10.1038/ nature 11740

6. McClung CA. Circadian genes, rhythms and the biology of mood disorders. Pharmacol Ther (2007) 114:222-32. doi:10.1016/j.pharmthera.2007. 02.003 
7. Hampp G, Ripperger JA, Houben T, Schmutz I, Blex C, Perreau-Lenz S, et al. Regulation of monoamine oxidase A by circadian-clock components implies clock influence on mood. Curr Biol (2008) 18:678-83. doi:10.1016/j. cub.2008.04.012

8. Partonen T, Treutlein J, Alpman A, Frank J, Johansson C, Depner M, et al. Three circadian clock genes Per2, Arntl, and Npas2 contribute to winter depression. Ann Med (2007) 39:229-38. doi:10.1080/07853890701278795

9. Chung S, Lee EJ, Yun S, Choe HK, Park SB, Son HJ, et al. Impact of circadian nuclear receptor REV-ERBalpha on midbrain dopamine production and mood regulation. Cell (2014) 157:858-68. doi:10.1016/j.cell. 2014.03.039

10. Jager J, O’Brien WT, Manlove J, Krizman EN, Fang B, Gerhart-Hines Z, et al. Behavioral changes and dopaminergic dysregulation in mice lacking the nuclear receptor Rev-erbalpha. Mol Endocrinol (2014) 28:490-8. doi:10.1210/ me.2013-1351

11. Schmutz I, Ripperger JA, Baeriswyl-Aebischer S, Albrecht U. The mammalian clock component PERIOD2 coordinates circadian output by interaction with nuclear receptors. Genes Dev (2010) 24:345-57. doi:10.1101/gad.564110

12. Ikeda E, Matsunaga N, Kakimoto K, Hamamura K, Hayashi A, Koyanagi S, et al. Molecular mechanism regulating 24-hour rhythm of dopamine D3 receptor expression in mouse ventral striatum. Mol Pharmacol (2013) 83:959-67. doi:10.1124/mol.112.083535

13. Akhisaroglu M, Kurtuncu M, Manev H, Uz T. Diurnal rhythms in quinpirole-induced locomotor behaviors and striatal D2/D3 receptor levels in mice. Pharmacol Biochem Behav (2005) 80:371-7. doi:10.1016/j.pbb. 2004.11.016

14. Civelli O, Bunzow JR, Grandy DK. Molecular diversity of the dopamine receptors. Annu Rev Pharmacol Toxicol (1993) 33:281-307. doi:10.1146/ annurev.pharmtox.33.1.281

15. Xu M, Koeltzow TE, Santiago GT, Moratalla R, Cooper DC, Hu XT, et al. Dopamine D3 receptor mutant mice exhibit increased behavioral sensitivity to concurrent stimulation of D1 and D2 receptors. Neuron (1997) 19:837-48. doi:10.1016/S0896-6273(00)80965-4

16. Ozburn AR, Falcon E, Twaddle A, Nugent AL, Gillman AG, Spencer SM, et al. Direct regulation of diurnal Drd3 expression and cocaine reward by NPAS2. Biol Psychiatry (2015) 77:425-33. doi:10.1016/j.biopsych. 2014.07.030

17. Kendler KS, Kessler RC, Walters EE, MacLean C, Neale MC, Heath AC, et al. Stressful life events, genetic liability, and onset of an episode of major depression in women. Am J Psychiatry (1995) 152:833-42. doi:10.1176/ ajp.152.6.833

18. Wolkowitz OM, Burke H, Epel ES, Reus VI. Glucocorticoids. mood, memory, and mechanisms. Ann N Y Acad Sci (2009) 1179:19-40. doi:10.1111/j.1749-6632.2009.04980.x

19. Carvalho LA, Garner BA, Dew T, Fazakerley H, Pariante CM. Antidepressants, but not antipsychotics, modulate GR function in human whole blood: an insight into molecular mechanisms. Eur Neuropsychopharmacol (2010) 20:379-87. doi:10.1016/j.euroneuro.2010.02.006

20. Massart R, Mongeau R, Lanfumey L. Beyond the monoaminergic hypothesis: neuroplasticity and epigenetic changes in a transgenic mouse model of depression. Philos Trans R Soc Lond B Biol Sci (2012) 367:2485-94. doi:10.1098/rstb.2012.0212

21. Tronche F, Kellendonk C, Kretz O, Gass P, Anlag K, Orban PC, et al. Disruption of the glucocorticoid receptor gene in the nervous system results in reduced anxiety. Nat Genet (1999) 23:99-103. doi:10.1038/12703

22. Wei Q, Lu XY, Liu L, Schafer G, Shieh KR, Burke S, et al. Glucocorticoid receptor overexpression in forebrain: a mouse model of increased emotional lability. Proc Natl Acad Sci U S A (2004) 101:11851-6. doi:10.1073/ pnas.0402208101

23. Deroche-Gamonet V, Sillaber I, Aouizerate B, Izawa R, Jaber M, Ghozland $\mathrm{S}$, et al. The glucocorticoid receptor as a potential target to reduce cocaine abuse. J Neurosci (2003) 23:4785-90.

24. Carpentier R, Sacchetti P, Segard P, Staels B, Lefebvre P. The glucocorticoid receptor is a co-regulator of the orphan nuclear receptor Nurr1.J Neurochem (2008) 104:777-89. doi:10.1111/j.1471-4159.2007.05055.x

25. Oster H, Challet E, Ott V, Arvat E, de Kloet ER, Dijk DJ, et al. The functional and clinical significance of the 24-h rhythm of circulating glucocorticoids. Endocr Rev (2016):er20151080. doi:10.1210/er.2015-1080
26. Okabe T, Chavan R, Fonseca Costa SS, Brenna A, Ripperger JA, Albrecht U. REV-ERBalpha influences the stability and nuclear localization of the glucocorticoid receptor. J Cell Sci (2016) 129:4143-54. doi:10.1242/jcs.190959

27. Lamia KA, Papp SJ, Yu RT, Barish GD, Uhlenhaut NH, Jonker JW, et al. Cryptochromes mediate rhythmic repression of the glucocorticoid receptor. Nature (2011) 480:552-6. doi:10.1038/nature10700

28. Schnell A, Sandrelli F, Ranc V, Ripperger JA, Brai E, Alberi L, et al. Mice lacking circadian clock components display different mood-related behaviors and do not respond uniformly to chronic lithium treatment. Chronobiol Int (2015) 32:1075-89. doi:10.3109/07420528.2015. 1062024

29. Charmandari E, Chrousos GP, Lambrou GI, Pavlaki A, Koide H, Ng SS, et al. Peripheral CLOCK regulates target-tissue glucocorticoid receptor transcriptional activity in a circadian fashion in man. PLoS One (2011) 6:e25612. doi:10.1371/journal.pone.0025612

30. Goriki A, Hatanaka F, Myung J, Kim JK, Yoritaka T, Tanoue S, et al. A novel protein, CHRONO, functions as a core component of the mammalian circadian clock. PLoS Biol (2014) 12:e1001839. doi:10.1371/journal.pbio. 1001839

31. Gould E, McEwen BS, Tanapat P, Galea LA, Fuchs E. Neurogenesis in the dentate gyrus of the adult tree shrew is regulated by psychosocial stress and NMDA receptor activation. J Neurosci (1997) 17:2492-8.

32. van Praag H, Kempermann G, Gage FH. Running increases cell proliferation and neurogenesis in the adult mouse dentate gyrus. Nat Neurosci (1999) 2:266-70. doi:10.1038/6368

33. Guzman-Marin R, Suntsova N, Stewart DR, Gong H, Szymusiak R, McGinty D. Sleep deprivation reduces proliferation of cells in the dentate gyrus of the hippocampus in rats. J Physiol (2003) 549:563-71. doi:10.1113/ jphysiol.2003.041665

34. Kempermann G, Kuhn HG, Gage FH. More hippocampal neurons in adult mice living in an enriched environment. Nature (1997) 386:493-5. doi:10.1038/386493a0

35. Gibson EM, Wang C, Tjho S, Khattar N, Kriegsfeld LJ. Experimental 'jet lag' inhibits adult neurogenesis and produces long-term cognitive deficits in female hamsters. PLoS One (2010) 5:e15267. doi:10.1371/journal.pone. 0015267

36. Golombek DA, Rosenstein RE. Physiology of circadian entrainment. Physiol Rev (2010) 90:1063-102. doi:10.1152/physrev.00009.2009

37. Eisch AJ, Petrik D. Depression and hippocampal neurogenesis: a road to remission? Science (2012) 338:72-5. doi:10.1126/science.1222941

38. Snyder JS, Soumier A, Brewer M, Pickel J, Cameron HA. Adult hippocampal neurogenesis buffers stress responses and depressive behaviour. Nature (2011) 476:458-61. doi:10.1038/nature10287

39. Goergen EM, Bagay LA, Rehm K, Benton JL, Beltz BS. Circadian control of neurogenesis. J Neurobiol (2002) 53:90-5. doi:10.1002/neu.10095

40. Kochman LJ, Weber ET, Fornal CA, Jacobs BL. Circadian variation in mouse hippocampal cell proliferation. Neurosci Lett (2006) 406:256-9. doi:10.1016/j. neulet.2006.07.058

41. Tamai S, Sanada K, Fukada Y. Time-of-day-dependent enhancement of adult neurogenesis in the hippocampus. PLoS One (2008) 3:e3835. doi:10.1371/ journal.pone.0003835

42. Gilhooley MJ, Pinnock SB, Herbert J. Rhythmic expression of per1 in the dentate gyrus is suppressed by corticosterone: implications for neurogenesis. Neurosci Lett (2011) 489:177-81. doi:10.1016/j.neulet.2010.12.011

43. Borgs L, Beukelaers P, Vandenbosch R, Nguyen L, Moonen G, Maquet P, et al. Period 2 regulates neural stem/progenitor cell proliferation in the adult hippocampus. BMC Neurosci (2009) 10:30. doi:10.1186/1471-220210-30

44. Schnell A, Chappuis S, Schmutz I, Brai E, Ripperger JA, Schaad O, et al. The nuclear receptor REV-ERBalpha regulates Fabp7 and modulates adult hippocampal neurogenesis. PLoS One (2014) 9:e99883. doi:10.1371/journal. pone. 0099883

45. Malik A, Kondratov RV, Jamasbi RJ, Geusz ME. Circadian clock genes are essential for normal adult neurogenesis, differentiation, and fate determination. PLoS One (2015) 10:e0139655. doi:10.1371/journal.pone. 0139655

46. Ali AA, Schwarz-Herzke B, Stahr A, Prozorovski T, Aktas O, von Gall C. Premature aging of the hippocampal neurogenic niche in adult 
Bmal1-deficient mice. Aging (Albany NY) (2015) 7:435-49. doi:10.18632/ aging. 100764

47. Bouchard-Cannon P, Mendoza-Viveros L, Yuen A, Kaern M, Cheng HY. The circadian molecular clock regulates adult hippocampal neurogenesis by controlling the timing of cell-cycle entry and exit. Cell Rep (2013) 5:961-73. doi:10.1016/j.celrep.2013.10.037

48. Kimiwada T, Sakurai M, Ohashi H, Aoki S, Tominaga T, Wada K. Clock genes regulate neurogenic transcription factors, including NeuroD1, and the neuronal differentiation of adult neural stem/progenitor cells. Neurochem Int (2009) 54:277-85. doi:10.1016/j.neuint.2008.12.005

49. Feng L, Hatten ME, Heintz N. Brain lipid-binding protein (BLBP): a novel signaling system in the developing mammalian CNS. Neuron (1994) 12:895-908. doi:10.1016/0896-6273(94)90341-7

50. De Rosa A, Pellegatta S, Rossi M, Tunici P, Magnoni L, Speranza MC, et al. A radial glia gene marker, fatty acid binding protein 7 (FABP7), is involved in proliferation and invasion of glioblastoma cells. PLoS One (2012) 7:e52113. doi:10.1371/journal.pone.0052113

51. Young JK, Heinbockel T, Gondre-Lewis MC. Astrocyte fatty acid binding protein-7 is a marker for neurogenic niches in the rat hippocampus. Hippocampus (2013) 23:1476-83. doi:10.1002/hipo.22200
52. Giachino C, Basak O, Lugert S, Knuckles P, Obernier K, Fiorelli R, et al. Molecular diversity subdivides the adult forebrain neural stem cell population. Stem Cells (2014) 32:70-84. doi:10.1002/stem.1520

53. Yin L, Wang J, Klein PS, Lazar MA. Nuclear receptor Rev-erbalpha is a critical lithium-sensitive component of the circadian clock. Science (2006) 311:1002-5. doi:10.1126/science.1121613

54. Robles MS, Humphrey SJ, Mann M. Phosphorylation is a central mechanism for circadian control of metabolism and physiology. Cell Metab (2016) 25(1):118-27. doi:10.1016/j.cmet.2016.10.004

Conflict of Interest Statement: The author declares that the research was conducted in the absence of any commercial or financial relationships that could be construed as a potential conflict of interest.

Copyright (๑) 2017 Albrecht. This is an open-access article distributed under the terms of the Creative Commons Attribution License (CC BY). The use, distribution or reproduction in other forums is permitted, provided the original author(s) or licensor are credited and that the original publication in this journal is cited, in accordance with accepted academic practice. No use, distribution or reproduction is permitted which does not comply with these terms. 